\title{
Improving Problem Solving and Solution Design Skills Using Problem Flow Coaches in Capstone Projects
}

\author{
Paul R. Rousseau ${ }^{1,}$ and Nikolai Khomenko ${ }^{2,3}$ \\ ${ }^{1}$ University of Windsor, Auto21 Researcher, Windsor Ontario Canada \\ ${ }^{2}$ TRIZ Master certified by Genrich Altshuller certificate Number 59, Ontario, Canada \\ ${ }^{3}$ OTSM expert at European Institute for Energy Research (EIFER), Karlsruhe, Germany \\ rousseau@uwindsor.ca; nikolai.khomenko@gmail.com
}

\begin{abstract}
Engineers are known for their ability to solve problems and design solutions to those problems. There is an increasing concern that engineering education is failing to prepare students to properly address complex, ill-structured problems in the context of multi-disciplinary teams in order to produce innovative solutions and designs. Instructional solutions such as coaching, active learning, helping students develop metacognitive skills, and the direct teaching of creative problem solving skills have been proposed and will be discussed. This paper introduces a concept of "problem flow coaches," who work closely with the capstone project teams. The problem flow coach, with expertise in systematic inventive problem solving methodologies, specifically OTSM (Russian language acronym for General Theory of Powerful Thinking) that is inclusive widely used problem solving methodology TRIZ, assists students in developing the cognitive and metacognitive skills needed to define, analyse and solve complex problems and develop innovative design concepts.
\end{abstract}

\section{The Evolution of Coaching Interventions and its Utilization in Engineering Education}

Coaching human performance has a long history. For the most part, coaching interventions have focused on sports to improve physical behaviours. In 1974, Tim Gallwey published "The Inner Game of Tennis". This book signalled an extension of coaching to the mental mindset of the athlete. About the same time, the life coach, business coach and executive coach industries began to grow. Thirty-five years later, coaching has become the chosen profession of thousands of people worldwide [9]. Coaching as an instructional technique has now migrated to engineering education.

With this rapid expansion of the coaching function the concept of "coach" and the function of "coaching" have come to mean many things, In sports, the coach is the one that brings out the best of players both in their physical and mental game. The intent of coaching interventions that target psychological functioning is not well defined.

In the business world, coaching appears to be attractive to executives who use it to learn new skills, improve their performance on the job, or to find purpose in their lives $[6,18]$. Individuals outside of the world of management and business also seek coaches to help them reach their life goals. The common thread is the development of a personal trusting relationship between a coachee and a coach, mainly for therapeutic reasons. The disciplines behind business and executive, and personal and life coaching are organizational development (OD) and human resource development (HRD). However, the quest to build a unique coaching profession, on par with $\mathrm{OD}$ and HRD, continues [9].

\subsection{Coaching in Education}

In education, the term coaching can be broadly described in the context of the teaching-learning process. A useful framework that comes from the personal/business coaching world is the "knowledgetransfer-continuum" [8], shown in Fig. 1.

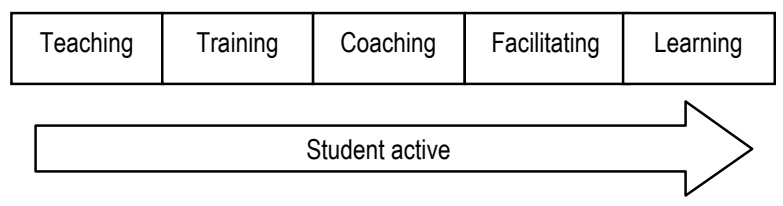

Figure 1. Knowledge-transfer continuum 
At the left end the teacher talks and the student absorbs, and at the right end the teacher listens and the student observes. Content is the main focus on the left side of the continuum and process on the right.

In general, the coach's role in this model is to supply some content (usually in the form of pointing the student to the content) and to encourage coachees to construct their own knowledge. Coaching involves asking the right questions and to structure the discourse in such a way that the student use and construct knowledge towards solving problems and designing solutions.

Coaching also enables students to develop metacognitive strategies, which is the basis of active learning. Metacognitive strategies are sequential processes that we use to control cognitive activities, and to ensure that cognitive goals (e.g., understanding a problem solving model) have been met. Coaches provide the scaffolding between teaching and learning so students can produce their own knowledge. The coach asks questions like "what's going on here?" and "what do we know more about?" and in this way encourages students to explore and discover, bridging the gap between teaching and learning [2].

Self-questioning is a common metacognitive comprehension monitoring strategy [25]. Fourth year engineering students carrying out capstone projects are close to entering their professions and are expected to manage their own thinking without external prompts. Metacognition is also the basis for self-directed learning, a critical learning outcome in higher education.

\subsection{Coaching Pre-College Students to be Better Problem Solvers}

Coaching students to be more effective problem solvers is well established at the K-12 level. An example of this kind of coaching is the Future Problem Solving Program. It is designed to help students develop skills for analyzing and solving problems. The FPSP, based on the work of E. Paul Torrance, is part of a larger international organization, Future Problem Solving Program International (FPSPI). K-12 teachers are trained to coach students in competitive problem solving events. Coaches are trained in creative problem solving process models and heuristics based on divergent thinking (brainstorming) methods [7].

\subsection{Coaching Engineering Students to be Better Problem Solvers}

There are a number of engineering programs that use coaches or a coaching function in capstone projects. In one case, non-technical coaches were used to facilitate communication among members of capstone project teams [23]; the study produced evidence of increased cohesion among the team members.

Another effort expands the faculty's role along the knowledge-transfer continuum, from teaching to coaching [22][30]. Coaches play three roles:

- mentor: provide support by guiding, being there, aware and helpful,

- mediator: a buffer between external reviewers and customers, and

- manager (facilitator): guiding the team's collaboration and design process.

Industrial advisors have been used as coaches in capstone projects. These coaches are volunteers from companies that sponsor the capstone projects. They communicate with students face-to-face and via email, faxes and telephone conferences [4].

A third way that coaching is used to support capstone projects involves faculty guiding and coaching students instead of teaching them. According to [19] "in this capstone course, the student's real life professional problem solving experience is accomplished primarily by the instructor's guiding and coaching the students rather than directing them in solving the problem."

Coaching as an instructional intervention is being used in capstone projects mainly as a way to facilitate communication and group process. Helping students work in teams is an important educational goal. Another major learning outcome for capstone projects is to provide students an opportunity to apply their knowledge and skills to solve real world problems and to design practical solutions. Increasingly, engineers are expected to produce more inventive solutions and designs that require applied creative thinking. The next section will describe efforts at developing creative problem solving skills in engineering students.

\section{Developing Creative Problem Solving and Inventive Design Skills}

The ability to solve problems and design solutions is the prime characteristic of a competent engineer. The question then is where in the engineering curriculum do students learn how to solve problems? More importantly, how do engineering undergraduates develop skills to solve complex problems that may be "ambiguous, open-ended and ill-structured" [17]. To be sure, they can solve textbook problems and pass course exams, however, the curriculum must address the need to deal with complex problems that require innovative solution. The review of the literature on engineering education [15] claims that: engineering 
curricula are too focused on engineering science, are too content driven, provide insufficient design experiences for students, and that graduates lack communication skills and team work experience.

There are many proposed solutions to these challenges. Using coaches, as described earlier, can help students develop communication and team process skills. A promising problem-based and project-based learning designs, which fall under the nomenclature ALE (active learning in engineering), can help develop problem-solving skills with the students actively participating in generating solutions [3]. These instructional design models build contexts within which skills to deal with complex problems can evolve. There may be, however, a need to be more explicit when developing these skills. Two ways of doing this is to teach and coach students so they can develop metacognitive skills, and to directly teach students creative problem solving and inventive solution design methods. Another way, coaching students to solve problems and design solutions in the context of capstone projects, will be described below .

\section{TRIZ (Theory of Inventive Problem Solving) in Engineering Education}

Genrich Altshuller progressively developed TRIZ, a Russian acronym for Theory for Inventive Problem Solving, between 1946 and 1998. TRIZ simultaneously developed a model of the problemsolving process to be used for developing practical tools for addressing inventive problems in engineering, namely ARIZ, and a set of methods and tools that enhance the practical efficiency of ARIZ. ARIZ was constantly developed and improved until 1985 through deductive unification of the theory.

Studies on TRIZ and TRIZ-based tools employed by engineering students are inconclusive [10][14][16][20]. Shields, who studied the impact of TRIZ tools in boosting creativity in capstone projects, concluded that enhanced creativity combined with a high level of academic performance leads to improved quality and innovation. Ogot's study concluded that using TRIZ does lead to an increase in creative output when compared to non-TRIZ teams who used brainstorming techniques. The results are uncertain since other factors like the knowledge base associated with TRIZ and learning style comfort were also part of the study. Ishihama suggests that TRIZ heuristics like the contradiction table can help engineering students use results of patent searches to develop better solutions. He argues that developing mastery of TRIZ is difficult, thus starting with simple tools like the contradiction table can encourage students to get on the TRIZ learning curve. Liu studied the combination of TRIZ and TOC (Theory of Constraints) as a way for engineering students to solve design problems.

\section{Barriers to Wider Use of TRIZ in Engineering Education}

There is an ongoing debate among engineering educators concerning the value of TRIZ as a legitimate methodology in engineering work, much of it couched in emotional and ideological language. TRIZ was developed in the former Soviet Union and its image in the West suffers from its association with a failed state and its ideology. Mastering TRIZ is also very difficult, partially because of its complexity and much of the original literature on TRIZ has yet to be translated from the Russian language.

In the middle of the 1990s serious TRIZ practitioners were eclipsed by problem solving consultants rushing to reap the commercial benefits from a selling the "bells and whistles" of an exciting new methodology. The methods (tools and techniques) of TRIZ were extracted and used independently and serious research of TRIZ theory and methodology was held back [11]. What is sold as TRIZ is actually a small and random set of tools that are minimally effective when used alone. A popular publication for TRIZ articles is the TRIZ Journal [4], which is not peer-reviewed. Consequently, the full potential of TRIZ methodology is not recognized. Many users of TRIZ-based tools employ parts of it as heuristics in an unsystematic manner. Indeed, using subsets of TRIZ tools and techniques produces results, but subpar to what the full methodology can help create. Classical TRIZ practiced by a well-trained certified TRIZ Master produces highly innovative solutions.

Another barrier is the methodology itself. Like all problem solving and solution design methodologies Classical TRIZ has its shortcomings. Classical TRIZ describes initial problem situations in terms of one or a few conflicting pairs of opposite technical contradictions. However, the necessity to analyze initial situations with hundreds of contradictions becomes apparent. Once a general description of a solution is obtained, it has to be transformed into a solution that is relevant to the specific situation. A second shortcoming is its difficulty in dealing with non-technical problems. Since TRIZ possesses a semantic founded upon engineering elements, its usage is more appropriate for engineering problems. But in the 1980's the need arose to deal simultaneously with engineering and non-engineering problems. Engineering problem solving demands the ability to generate a solution using data that is 
incomplete, while at the same time meeting client's need, which may be conflicting and solutions that minimize negative impact on social and physical environment and all of this at the lowest cost possible [22]. Finally, the last iteration of problem-solving process ARIZ was in 1985, and much has changed since then. To improve the ability of TRIZ to solve complex cross disciplinary problems, Altshuller proposed transforming Classical TRIZ into a general approach to problem solving and renamed it "General Theory of Powerful Thinking" the Russian acronym being OTSM [1].

\section{General Theory of Powerful Thinking, OTSM}

OTSM technologies overcome the limitations of ARIZ. Henceforth is a presentation of the "Problem Flow Networks" (PFN) approach that plays the same role in OTSM as ARIZ in Classical TRIZ [17].

\subsection{Improving ARIZ: The Problem Flow Network (PFN) Approach}

The canonical formulation of a problem in Classical TRIZ is the contradiction. When dealing with complex problems, one often tries to reduce the complexity by dividing the problem into sub-problems. This method is relevant when sub problems are independent, but in complex situations they are not. Conversely, the given problem may be a sub problem of a super problem. Classical TRIZ provides technologies for dealing with one contradiction at a time. Complex problem situations are characterized by a large set of parameters and interference of the elements involved in the problem. PFN approach allows the representation and analysis of several contradictions and problems at once.

\subsection{The Problem Flow Coach}

The problem flow coach guides the capstone project team to move through the PFN stages (below) in order to produce creative design solutions to complex problems. The focus of each stage is:

- Build Network of Problems

- Construct Network of Contradictions

- Generated Network of Parameters

- Produce List of Partial Solutions

- Make List of Partial Concepts

- Describe Satisfactory Conceptual Solution

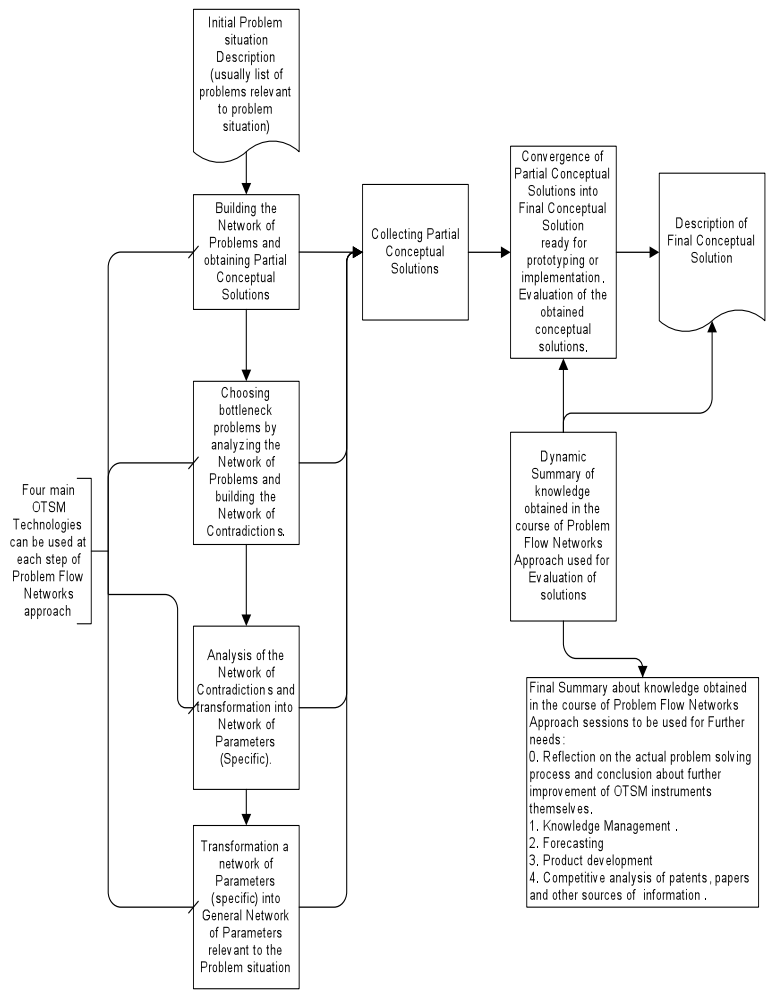

Figure 2. The problem flow

\subsection{Network of Problems.}

A usual starting point is a list of problems, difficulties, inconveniences and questions relevant to the problem situation made by professionals dealing with the problem. Then through a process using OTSM rules and technologies, this initial list of problems is changed into a Network of Problems. This network can be considered as a semantic network or as a graph; it could be presented graphically or in the shape of a connectivity matrix. Both methods of representation are used to analyze the Network of Problems. The graph also contains nodes that present known Partial Solutions of certain problem nodes. Problems that are generated by Partial Solutions are also presented. The graph organization produces a "big picture" of the problem situation and various options to solve it can be deduced. Its analysis leads to disclosure of a set of key problems of the whole problematic situation.

Once the Network of Problems becomes stable and the key problems are extracted, the set of technical contradictions that are behind the set of key problems can be disclosed and used as an initial list of contradictions to construct the Network of Contradictions. Key problems could be identified by formal rules based on topology of the sub-graphs. 


\subsection{Network of Contradictions.}

The Network of Problems is useful for understanding the problem and narrowing the area of research in order to construct a solution according to one of the main ideas of Classical TRIZ and OTSM) [12]. The Network of Contradictions contains the set of elements of the system and its environment that are connected to the key problem discovered in the Network of Problems. Uncovering the contradictions enables the search for resources of the problem situation involved in the Network of Contradictions and the transformation of the network of contradictions into the Network of Parameters according to the rules of Altshuller's ARIZ and OTSM Contradiction Technology. Problems do appear in a technical system due to a conflict between the values of a parameter., for example physical contradictions for physical parameters, chemical contradiction for chemical parameters, and so on.

Altshuller called this kind of conflict "Physical Contradiction" and considered it as the deep root of a Technical Contradiction, which is a contradiction between two technical or evaluation parameters of the same system. A physical contradiction is a contradiction where a parameter is required to simultaneously take different values; therefore, in OTSM this kind of contradiction is named "Contradiction of Parameters."

\subsection{Network of Parameters}

The Network of Parameters has the same function as the Physical Contradictions in ARIZ. For engineering problems this network gives a deep understanding of the discrepancy between the human's wishes (target of the problem-solving process) and the natural laws of nature described in science.

Switching from one type of contradiction to another in Classical ARIZ lead us to the deep roots of the initial problem. The OTSM PFN approach switches from one kind of network to another one, leading to the deep roots of initial complex interdisciplinary problem.

\subsection{Producing Solutions}

OTSM proposes methods that facilitate effective combinations of concepts that are not solutions of the problem but that contain ideas that partially solve the problem; these concepts are called "partial solutions". Partial solutions are identified along the problem solving process based on various kinds of standard and other typical solutions. Along this process the solver aggregates partial solutions into Converged
Conceptual Solutions by the means of OTSM knowledge, his personal knowledge and skills of specialists of various but targeted domains. Convergence of partial solutions is performed in order to systematically increase positive effects while systematically decreasing possible negative effects. When positive effects sufficiently surpass the negative ones, the convergent concept becomes the Final Conceptual Solution; otherwise, it is considered as a new partial solution and generation of partial solutions continue in respect of OTSM rules and mechanisms

The Problem Flow Network process produces relevant information about the problem making it explicit and organized. This knowledge can be used in order to build criteria for comparing satisfactory Conceptual Solutions or for evaluating Partial Conceptual Solutions throughout the problem solving process. Furthermore, Networks of Parameters can be useful to forecast some consequences of the implementation of certain solutions.

\section{Conclusion}

Being proposed in this paper is the introduction of a new role to support capstone projects that of the problem flow coach (PFC). Research on the effectiveness of introducing problem flow coaches is needed. The research design can build on work already done measuring the effectiveness of using non-technical coaches to support capstone projects as cited earlier in this paper. The parameters yet to be researched are the effectiveness of using coaches who will not only facilitate team development and resolve conflicts but guide the problem solving and solution design process using OTSM or an analogous framework as a methodology. Other systematic problem solving approaches, other than OTSM, should also be tested to investigate if it is OTSM in particular, or a comparable systematic comprehensive approach, that has to most influence in producing innovative project outcomes.

PFCs do not have to be engineers. The main qualifications are that they have well developed interpersonal communication, facilitating and team process skills, and knowledge of and skills in systematic inventive problem solving and solutions design, specifically the methodology of OTSM. Problem flow coaches who have expertise in other methodologies such as Value Engineering and Six Sigma would add value to their work. A training program to certify PFCs needs to be developed. To insure the integrity of the work of PFCs, a toolkit that includes software applications, case studies and other resources to support PFC work needs to be developed. 


\section{Acknowledgements}

The authors gratefully acknowledge support from the Auto21 program, and project EC 303-ESP in particular. They also would like to thank Dr. Zbigniew Pasek from Industrial and Manufacturing Systems Engineering at the University of Windsor for his comments and suggestions.

\section{References}

[1] Altshuller, GS. "The History of ARIZ," Journal of TRIZ, (1992) Vol. 3, No. 1 (English).

[2] Benjamin C. Implications of introducing problem-based learning in a traditionally taught course. Engineering Education: Journal of the Higher Education Academy Engineering Subject Centre (2006), Vol 1, No 1

[3] Bridge, John W. "Incorporating active learning in an engineering materials science course." ASEE annual conference (2001):5703-5713

[4] Counce, R M. "An honors capstone design experience utilizing authentic industrial projects." The international journal of engineering education 17.4 (2001):396-9

[5] Evidence-Based Coaching Handbook, (2006) Wiley New York, N.Y.

[6] Fournies, F. F. Coaching for improved work performance. Liberty Hall Press. 1987).

[7] Future Problem Solving Program International website. Retrieved June 30, 2009 from http://www.fpspi.org/index.html

[8] Hamer, E. The Knowledge-Transfer Continuum. Retrieved June 30, 2009 from the eHamer Associates website http://www.hamerassociates.ca/ee/index.php/site/performance pointers/the $\mathrm{kn}$ owledge transfer continuu/

[9] Hamlin, R. Toward a profession of coaching. International Journal of Evidence Based Coaching and Mentoring (2009)

[10] Ishihama, M. "Training students on the TRIZ method using a patent database." International Journal of Technology Management 25.6 (2003):568-78.

[11] Karasik, Y. The aim and scope. Retrieved July 2, 2009 from The anti TRIZ-journal http://www3.sympatico.ca/karasik/ (2009) 8, (5.)

[12] Khomenko, N.; De Guio, R. "A framework for OTSMTRIZ-based computer support to be used in complex problem management." International Journal of Computer Applications in Technology 30.1 (2007):88-104.
[13] Khomenko, N; Kucharavy, D."OTSM problem solving process: Solutions and their classification," TRIZ Future 2002 Conference Strasbourg, France

[14] Liu, Y. Innovation design and application based o TOC and TRIZ. ICMA 2004 - Proceedings of the International Conference on Manufacturing Automation: Advanced Design and Manufacturing in Global Competition, 2004, 117

[15] Mills, Julie E. "Engineering education - is problembased or project-based learning the answer." Australasian journal of engineering education., online publication 200304.

http://www.aaee.com.au/jounal/2003/mills treagust03.pdf

[16] Ogot, M. "Systematic creativity methods in engineering education: a learning styles perspective." The International journal of engineering education 22.3 (2006):566-76.

[17] Olafsson, Sigurdur. "Engineering problem solving in industrial engineering curriculum reform." ASEE Annual Conference and Exposition, Conference Proceedings (2005):5503-5515

[18] Popper, M. Coaching on leadership. Leadership \& Organization Development Journal, (1992) 13(7), 15-18.

[19] Ruud, Clayton O. "Developing and conducting an industry based capstone design course." Proceedings Frontiers in Education Conference 2(1997):644-647.

[20] Shields, Elvin. "Fostering creativity in the capstone engineering design experience." ASEE Annual Conference and Exposition, Conference Proceedings (2007)

[21] Stober, D. Coaching from the humanistic perspective in Evidence Based Coaching Handbook: Putting Best Practices to Work for Your Clients Stober, D. and Grant A. M. (eds) Wiley, New York, (2006)

[22] Taylor, D G. "Training faculty to coach capstone design teams." The International journal of engineering education $17.4(2001): 353-8$.

[23] Seat, J.E. Making design teams work. TechnologyBased Re-Engineering. Engineering Education. Proceeding of Frontiers in Education FIE'96 26th Annual Conference (Cat. No.96CH35946), (1996) 272-5 vol.1,

[24] Torrance, E.P. Handbook for training future problem solving teams. Cedar Rapids, IA. Future Problem Solving Program (1981) Vol. 7, No.1

[25] Vos, H. "Developing metacognition: a basis for active learning." European journal of engineering education 29.4 (2004): 